\title{
Genetic analysis of milk urea nitrogen and relationships with yield and fertility across lactation
}

\author{
S. Mucha ${ }^{*}{ }^{1}$ and E. Strandberg* \\ ${ }^{*}$ Department of Animal Breeding and Genetics, Swedish University of Agricultural Sciences, Box 7023, 75007 Uppsala Sweden \\ †Department of Genetics and Animal Breeding, Poznan University of Life Sciences, Wolynska 33, 60-637 Poznan Poland
}

\begin{abstract}
The aim of this project was to investigate the relationship of milk urea nitrogen (MUN) with 3 milk production traits [milk yield (MY), fat yield (FY), protein yield (PY)] and 6 fertility measures (number of inseminations, calving interval, interval from calving to first insemination, interval from calving to last insemination, interval from first to last insemination, and pregnancy at first insemination). Data consisted of 635,289 test-day records of MY, FY, PY, and MUN on 76,959 first-lactation Swedish Holstein cows calving from 2001 to 2003, and corresponding lactation records for the fertility traits. Yields and MUN were analyzed with a random regression model followed by a multitrait model in which the lactation was broken into 10 monthly periods. Heritability for MUN was stable across lactation (between 0.16 and 0.18), whereas MY, FY, and PY had low heritability at the beginning of lactation, which increased with time and stabilized after 100 $\mathrm{d}$ in milk, at $0.47,0.36$, and 0.44 , respectively. Fertility traits had low heritabilities (0.02 to 0.05). Phenotypic correlations of MUN and milk production traits were between 0.13 (beginning of lactation) and 0.00 (end of lactation). Genetic correlations of MUN and MY, FY, and PY followed similar trends and were positive $(0.22)$ at the beginning and negative $(-0.15)$ at the end of lactation. Phenotypic correlations of MUN and fertility were close to zero. A surprising result was that genetic correlations of MUN and fertility traits suggest a positive relationship between the 2 traits for most of the lactation, indicating that animals with breeding values for increased MUN also had breeding values for improved fertility. This result was obtained with a random regression model as well as with a multi-trait model. The analyzed group of cows had a moderate level of MUN concentration. In such a population MUN concentration may increase slightly due to selection for
\end{abstract}

Received October 9, 2010.

Accepted August 3, 2011.

${ }^{1}$ Corresponding author: sebastianmucha@gmail.com improved fertility. Conversely, selection for increased MUN concentration may improve fertility slightly.

Key words: milk urea nitrogen, cow fertility, random regression, multi-trait

\section{INTRODUCTION}

Milk urea nitrogen is a common tool used for evaluation of diet composition and feeding disorders. Urea is synthesized primarily in the liver and originates from ammonia, which comes from protein degradation in the rumen or from deamination of amino acids in excess of requirements (Gustafsson and Palmquist, 1993). Limited amounts can also be derived from arginine catabolism in the mammary gland (Nousiainen et al., 2004). Urea is transported in blood to the kidneys and part of it diffuses to milk (Gustafsson and Palmquist, 1993).

Urea is related to dietary $\mathrm{CP}$ intake, percentage of rumen degradable and undegradable protein (Baker et al., 1995), and the ratio of nitrogen to water-soluble carbohydrates (Trevaskis and Fulkerson, 1999). It is positively associated with stage of lactation (Trevaskis and Fulkerson, 1999; Godden et al., 2001). According to some reports, it is negatively related to milk protein content (Trevaskis and Fulkerson, 1999; Godden et al., 2001), whereas others have found a positive relationship (Stoop et al., 2007). Milk urea $\mathrm{N}$ is also negatively related to SCC (Godden et al., 2001). On the other hand, it is positively associated with such factors as cow age (Trevaskis and Fulkerson, 1999; Wood et al., 2003) and parity (Godden et al., 2001) and can depend on season and grazing system (Trevaskis and Fulkerson, 1999). Apart from that, herd test-day (HTD) has a highly significant effect on MUN concentration (Wood et al., 2003). In addition, sampling time (a.m. or p.m.) and feeding to sampling interval has been reported to affect MUN concentrations (Godden et al., 2001). Milk yield has been found by some to be positively related to MUN (Godden et al., 2001), whereas others reported a negative relationship (Ismail et al., 1996; Trevaskis and Fulkerson, 1999).

Milk urea $\mathrm{N}$ has been also used to investigate infertility problems related to excess dietary nitrogen (Trevaskis and Fulkerson, 1999). Some authors have 
found a relationship between the 2 traits (Butler et al., 1996; Rajala-Schultz et al., 2001; Guo et al., 2004; Mitchell et al., 2005), whereas others failed to confirm this relationship (Barton et al., 1996; Trevaskis and Fulkerson, 1999; Cottrill et al., 2002). The aim of this project was to investigate the relationship of MUN with 3 milk production traits: milk yield (MY), fat yield $(\mathbf{F Y})$, and protein yield (PY) and 6 fertility measures: number of inseminations to conception (NINS), calving interval (CI), interval from calving to first insemination (CFI), interval from calving to last insemination (CLI), interval from first to last insemination (FLI), and pregnancy at first insemination (PFI), which was a binary trait taking a value of 1 if a cow was pregnant after the first insemination and 0 otherwise.

\section{MATERIALS AND METHODS}

\section{Data}

The research was based on data provided by the Swedish Dairy Association (Stockholm). The study used 3 data sets, which were combined after initial editing. The first data set contained test-day records on urea concentration measured using infrared spectroscopy and sampling date. The second data set contained test-day data on milk yield, fat yield, and protein yield, herd (6,074 herds), age at calving (20 to 38 mo), lactation number, calving date, and day in lactation (5 to 400 DIM). The third data set contained the fertility traits described previously.

For the analysis, 635,289 records on 76,959 Swedish Holstein cows calving from 2001 to 2003 were used. Only first-lactation cows with more than 3 test-day observations remained in the data set; each test-day had to have at least 2 records each. The data were edited to eliminate records with unrealistic urea concentrations $(<1$ and $>10 \mathrm{mmol} / \mathrm{L})$. Lactation length was restricted to 400 DIM. Number of daughters per sire was at least 50 .

\section{Estimation of (Co)Variance Components}

Estimates of (co)variance components were obtained by the average information-REML algorithm in the DMU package (Madsen and Jensen, 2008). The genetic analysis was done using the following random regression sire model for MUN, MY, FY, and PY:

$$
\begin{aligned}
y_{i j k l n o} & =\text { age }_{i}+\text { season }_{j}+h t d_{k}+\mathbf{L}^{\prime}\left(D I M_{l}\right) \mathbf{b} \\
& +\mathbf{L}^{\prime}\left(D I M_{l}\right) \mathbf{s}_{n}+\mathbf{L}^{\prime}\left(D I M_{l}\right) \mathbf{p e}_{n o}+e_{i j k l n o},
\end{aligned}
$$

where $y_{i j k l n o}$ is test-day observation at $D I M_{l}$ of cow $o$, sired by the $n$th sire, with age at calving $i$ and season of calving $j$ on HTD $k$; $a g e_{i}$ is the fixed effect of age at first calving (in months, 20 to 38); season $_{j}$ is the fixed effect of calving season [summer (June to August), autumn (September to November), winter (December to February), and spring (March to May)]; $h t d_{k}$ is the fixed effect of HTD $k ; \mathbf{b}$ is the $1 \times 9$ vector of fixed regression coefficients on Legendre polynomials (eighth order) of $D I M_{i} ; \mathbf{s}_{n}$ is the $1 \times 5$ vector of random regression coefficients (Legendre polynomials of fourth order) for the effect of sire $n$; $\mathbf{p e}_{n o}$ is the $1 \times 5$ vector of random regression coefficients (Legendre polynomials of fourth order) for the permanent environment effect of daughter $o$ sired by sire $n ; \mathbf{L}^{\prime}(D I M)$ is the row vector of Legendre polynomials for $D I M_{l}$ (Kirkpatrick et al., 1990), of size 9,5 , and 5 for the 3 regressions, respectively; and $e_{i j k l n o}$ is the random residual effect.

Random effects were assumed to be normally distributed with zero means and covariance structure:

$$
\operatorname{Var}\left[\begin{array}{c}
\mathbf{s} \\
\mathbf{p e} \\
e
\end{array}\right]=\left[\begin{array}{ccc}
\mathbf{A} \otimes \mathbf{S} & 0 & 0 \\
& \mathbf{I} \otimes \mathbf{P E} & 0 \\
\mathbf{s y m m} & & \mathbf{I} \sigma_{e}^{2}
\end{array}\right],
$$

where $\mathbf{A}$ is the additive genetic relationship matrix, $\mathbf{S}$ and $\mathbf{P E}$ are $5 \times 5$ (co)variance matrices of the random regression coefficients for the sire and permanent environment effects, respectively, and $\mathbf{I}$ are identity matrices.

The sire model for fertility traits (NINS, CI, CFI, CLI, FLI, PFI) was

$$
y_{i j k n o}=\text { age }_{i}+\text { season }_{j}+h y_{k}+s_{n o}+e_{i j k n o},
$$

where $y_{i j k n o}$ is the observation for one of the fertility traits, age ${ }_{i}$ and season $_{j}$ are as in model [1], $h y_{k}$ is the fixed effect related to herd-year of calving, $s_{n o}$ is the random effect of sire $n$ of cow $o$, and $e_{i j k n o}$ is the random residual effect.

The variance-covariance structures for the bivariate models were as follows:

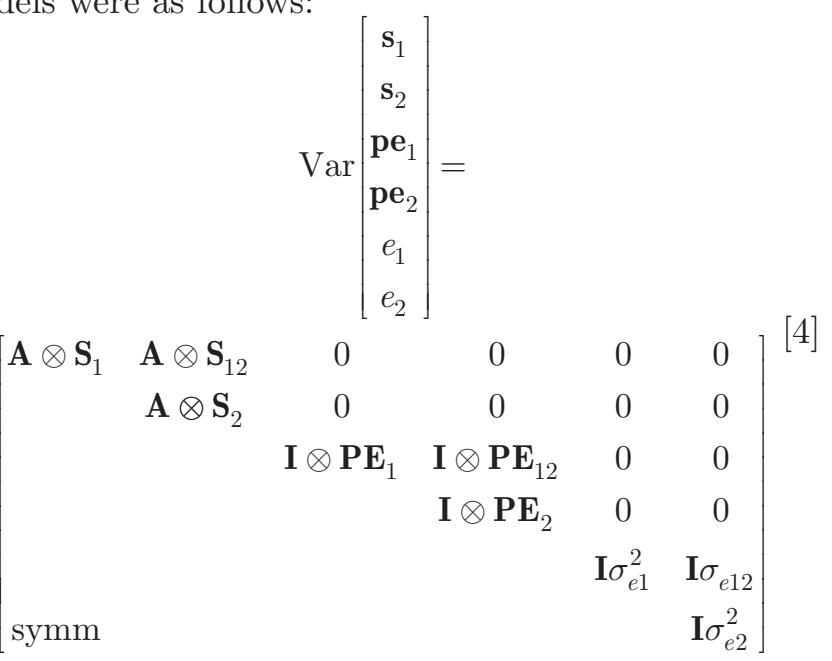


where indices 1 and 2 indicate the 2 traits. If the second trait followed model [3], $\mathbf{S}_{12}$ contained only one column and $\mathbf{S}_{2}$ only one value, and $\mathbf{P} \mathbf{E}_{12}$ and $\mathbf{P} \mathbf{E}_{2}$ were nonexistent.

An additional analysis for MUN, MY, FY, PY, and fertility traits was performed with a multi-trait model, which was identical to model [3], except that it included a different covariance structure:

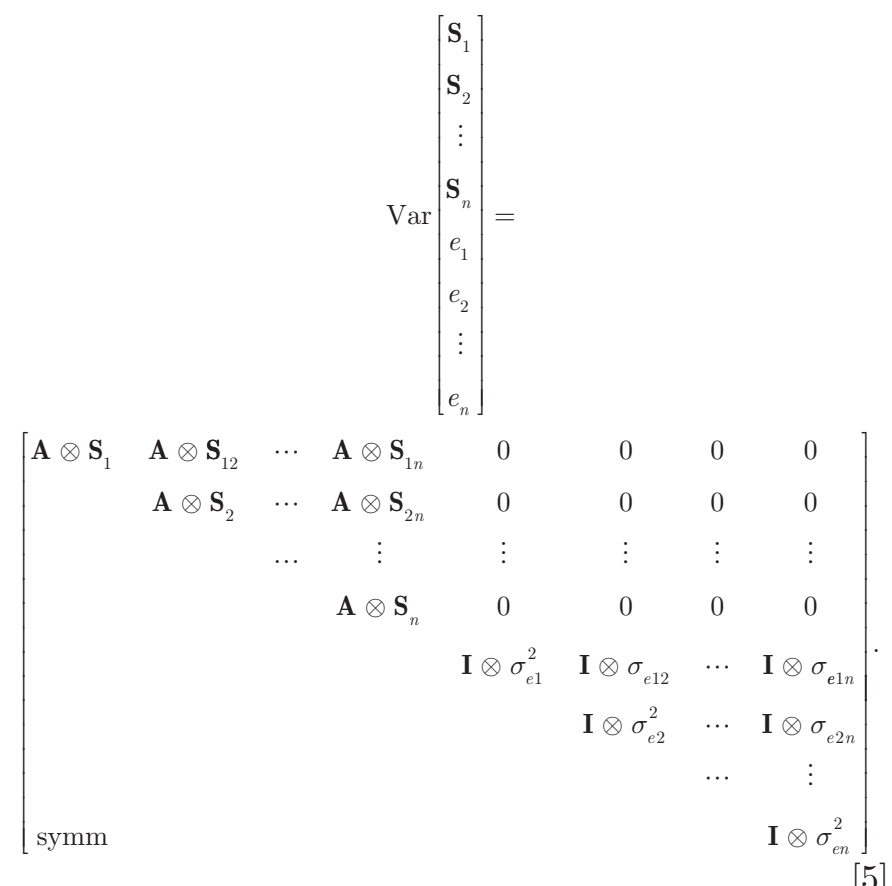

In this analysis, only records between 5 and 300 DIM were included. They were divided into ten 30 -d periods (except for the first period, which had only $25 \mathrm{~d}$ ). Each period was treated as a separate trait for MUN, MY, FY, and PY.

\section{Calculation of Parameters}

Heritability on ith DIM for MUN, MY, FY, and PY was calculated as

$$
\hat{h}_{i}^{2}=\frac{4 \times \hat{\sigma}_{s i}^{2}}{\hat{\sigma}_{s i}^{2}+\hat{\sigma}_{p e i}^{2}+\hat{\sigma}_{e}^{2}},
$$

where $\hat{\sigma}_{s i}^{2}$ and $\hat{\sigma}_{p e i}^{2}$ are the estimates of sire and permanent environment variance, respectively, on $i$ th DIM, and $\hat{\sigma}_{e}^{2}$ is the estimated residual variance. The sire and permanent environment variances were calculated as $\hat{\sigma}_{s i}^{2}=\mathbf{L}^{\prime}\left(D I M_{i}\right) \hat{\mathbf{S}} \mathbf{L}\left(D I M_{i}\right)$ and $\hat{\sigma}_{p e i}^{2}=\mathbf{L}^{\prime}\left(D I M_{i}\right) \widehat{\mathbf{P E}} \mathbf{L}\left(D I M_{i}\right)$. Heritability for NINS, CI, CFI, CLI, FLI, and PFI was estimated as

$$
\hat{h}^{2}=\frac{4 \times \hat{\sigma}_{s}^{2}}{\hat{\sigma}_{s}^{2}+\hat{\sigma}_{e}^{2}} .
$$

Genetic and phenotypic correlations were estimated from the bivariate analyses. Genetic and permanent environment covariance estimates among MUN, MY, FY, and PY on ith DIM were calculated as $\hat{\sigma}_{s i 12}=\mathbf{L}^{\prime}\left(D I M_{i}\right) \hat{\mathbf{S}}_{12} \mathbf{L}\left(D I M_{i}\right)$ and $\hat{\sigma}_{p e i 12}=\mathbf{L}^{\prime}\left(D I M_{i}\right) \widehat{\mathbf{P E}_{12}} \mathbf{L}\left(D I M_{i}\right)$, respectively. The phenotypic covariance was the sum of the sire, permanent environment, and residual covariances. For MUN and fertility traits, genetic covariances on ith DIM were calculated as above but with the last $\mathbf{L}\left(D I M_{i}\right)$ removed. In case of the multi-trait analysis of MUN and fertility, both $\mathbf{L}\left(D I M_{i}\right)$ were removed.

The standard errors for heritability and genetic and phenotypic correlations were calculated using the methodology proposed by Fischer et al. (2004), with the interpretation proposed by Frigo et al. (2010).

\section{RESULTS}

Means, coefficients of variation, minimum, and maximum values for MUN and milk production traits are presented in Table 1. The concentration of MUN demonstrated minor changes during lactation. It increased from 20 to 75 DIM, when it reached a maximum value of $5 \mathrm{mmol} / \mathrm{L}(14 \mathrm{mg} / \mathrm{dL})$. It remained at this level until 200 DIM and then decreased to $4.6 \mathrm{mmol} / \mathrm{L}$. Daily milk yield reached a peak $(30 \mathrm{~kg})$ at around 50 DIM and started decreasing at around 90 DIM. Fat and protein yields followed a similar trend and were the highest at around 50 DIM, with peaks of 1.17 and $0.94 \mathrm{~kg}$, respectively.

\section{Heritability Estimates}

Heritability of MUN (based on the random regression and the multi-trait model) was around $0.17 \pm 0.007$ during the entire lactation, with the highest value at the beginning of lactation of $0.18 \pm 0.007$ (Figure 1). Based on the random regression model, MY, FY, and PY had the highest heritability in the middle of lactation at $0.47 \pm 0.011,0.36 \pm 0.010$, and $0.44 \pm 0.011$, respectively. Multi-trait models revealed a similar tendency, although with lower values of $0.35 \pm 0.011,0.29$ \pm 0.010 , and $0.33 \pm 0.011$, respectively. All of the milk production traits had lower heritability at the beginning than at the end of lactation (Figure 1). Fertility traits had low heritabilities, ranging from $0.02 \pm 0.002$ to $0.05 \pm 0.004$ (Table 1 ).

\section{Genetic and Phenotypic Correlations}

Genetic correlations (based on random regression models and multi-trait models) of MUN with CFI, CLI, 
Table 1. Mean, minimum, and maximum values, CV, and heritability $\left(\mathrm{h}^{2}\right)$ estimates $( \pm$ SE) for MUN, milk production traits, and fertility measures

\begin{tabular}{|c|c|c|c|c|c|c|c|}
\hline Trait $^{1}$ & $\mathrm{n}$ & Mean & Minimum & Maximum & $\mathrm{CV}$ & \multicolumn{2}{|c|}{$h^{2}$} \\
\hline MUN (mmol/L) & 634,405 & 4.86 & 1.0 & 10.0 & 0.25 & $0.16 \pm 0.007$ & $0.18 \pm 0.007$ \\
\hline Fat yield $(\mathrm{kg})$ & 633,639 & 1.07 & 0.4 & 2.0 & 0.23 & $0.16 \pm 0.008$ & $0.36 \pm 0.010$ \\
\hline Protein yield $(\mathrm{kg})$ & 633,740 & 0.91 & 0.4 & 2.0 & 0.21 & $0.15 \pm 0.008$ & $0.44 \pm 0.011$ \\
\hline CI $(d)$ & 59,056 & 416.09 & 271 & 700 & 0.16 & \multicolumn{2}{|c|}{$0.04 \pm 0.004$} \\
\hline FLI (d) & 64,041 & 38.14 & 0 & 364 & 1.43 & \multicolumn{2}{|c|}{$0.03 \pm 0.003$} \\
\hline PFI $(0 / 1)$ & 64,041 & 0.43 & 0 & 1 & 1.16 & \multicolumn{2}{|c|}{$0.02 \pm 0.002$} \\
\hline NINS & 66,257 & 1.98 & 1 & 13 & 0.69 & \multicolumn{2}{|c|}{$0.04 \pm 0.003$} \\
\hline
\end{tabular}

${ }^{1}$ Fertility measures: $\mathrm{CI}=$ calving interval; $\mathrm{CFI}=$ interval from calving to first insemination; $\mathrm{CLI}=$ interval from calving to last insemination; $\mathrm{FLI}=$ interval from first to last insemination; PFI = pregnancy at first insemination; NINS $=$ number of inseminations to pregnancy.

FLI, and NINS were negative and followed a similar trend during lactation (Figure 2). Genetic correlation between MUN and calving interval followed a similar pattern, except for the first $50 \mathrm{~d}$, when it was positive. However, in the multi-trait analysis, the correlation was equal to zero at the beginning and became negative in the subsequent months of lactation. Consistently, in both types of analysis, the genetic correlation between MUN and PFI started out negative but turned positive from d 35 onward (Figure 2). Genetic correlations of MUN with fertility traits had similar standard errors, which ranged from 0.125 at the beginning of lactation to 0.082 at the end of lactation. Phenotypic correlations between MUN and all of the fertility traits were constant during lactation and close to zero, with standard errors between 0.006 and 0.005 .

Genetic correlation of MUN with MY, FY, and PY were very similar (Figure 3 ). They were weakly positive until 230 DIM and negative thereafter, ranging from $0.22 \pm 0.082$ to $-0.15 \pm 0.065$ from the beginning to the end of lactation. Phenotypic correlations for MUN and the milk production traits also followed a similar

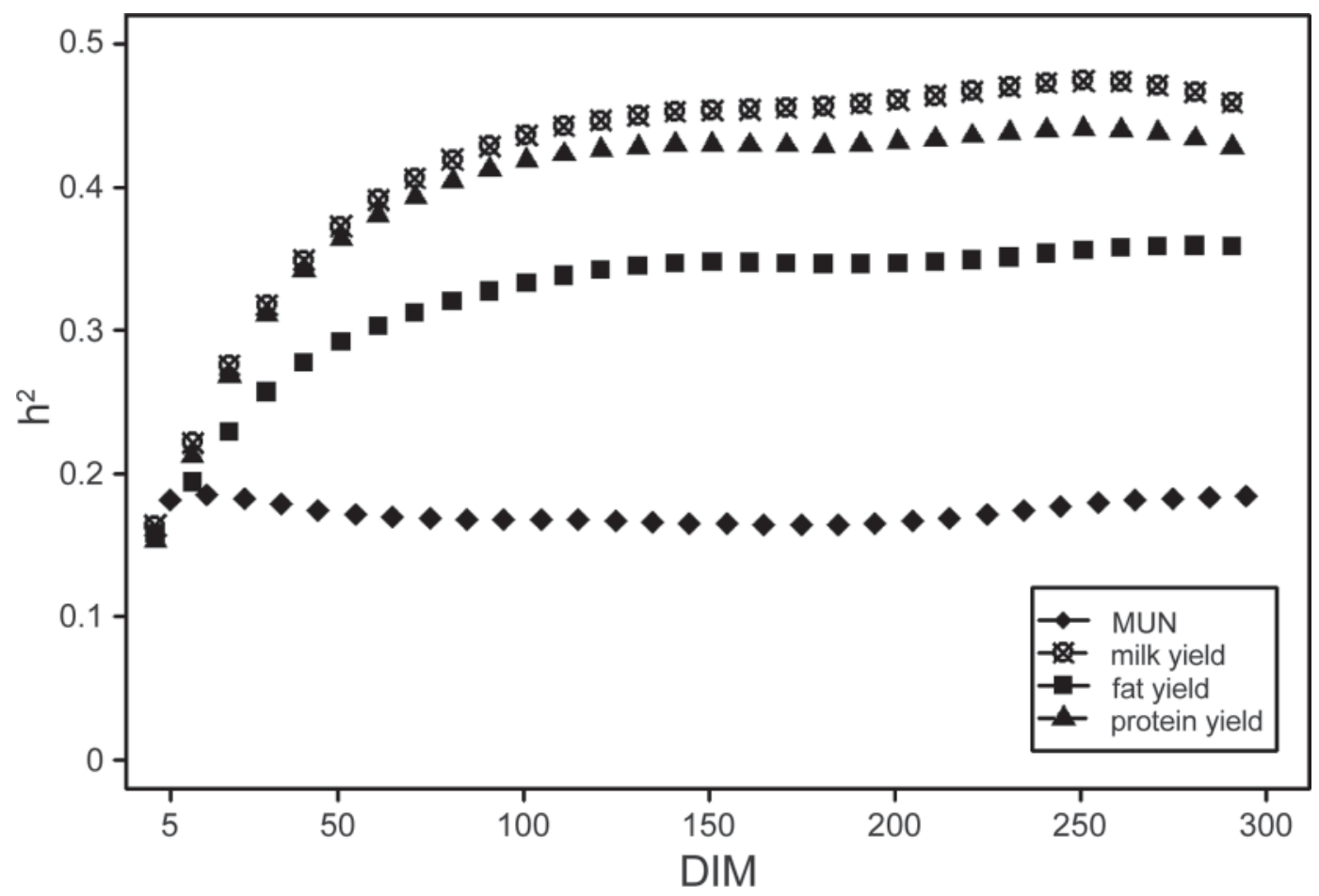

Figure 1. Trend for heritability of MUN, milk yield, protein yield, and fat yield of first-lactation Swedish Holstein cows during $300 \mathrm{~d}$ of lactation, based on the random regression model. 
trend and ranged between $0.01 \pm 0.010$ and $0.13 \pm$ 0.009 .

\section{DISCUSSION}

\section{MUN}

The average MUN concentration of $4.86 \mathrm{mmol} / \mathrm{L}$ $(13.6 \mathrm{mg} / \mathrm{dL})$ found in the current research was low compared with values reported in the literature, where MUN ranged between 10.73 and $20.39 \mathrm{mg} / \mathrm{dL}$ (RajalaSchultz et al., 2001; Wood et al., 2003; Guo et al., 2004; Miglior et al., 2007; Stoop et al., 2007). Similar concentrations $(4.8 \mathrm{mmol} / \mathrm{L})$ were reported by Godden et al. (2001) and Eicher et al. (1999) in some of the Quebec dairy herds. The lactation curve of MUN did not seem to be affected by the milk yield curve and thus did not change much with stage of lactation. Milk urea $\mathrm{N}$ was lowest at the beginning of lactation and reached a peak value of $5 \mathrm{mmol} / \mathrm{L}$ at around 75 DIM, where it remained until 180 DIM and was only slightly decreasing until the end of lactation. This finding is in agreement with findings of other authors (e.g., Godden et al., 2001). On the other hand, the curve obtained for MUN differs from that presented by Wood et al. (2003), who reported an increase of MUN concentration after the peak of lactation. The difference may have been due to management or nutrition, although no clear explanation can be given.

\section{Heritabilities}

Heritability estimates for MUN found in the current research are within the range of 0.13 to 0.22 reported by some researchers (Mitchell et al., 2005; Stoop et al., 2007; Bastin et al., 2009; Hossein-Zadeh and Ardalan, 2011), but much lower than the estimates of Miglior et al. (2007) and Wood et al. (2003) which were 0.38 and 0.59 , respectively. This discrepancy can be explained in part by the differences in structure of the data, such as herd size, number of records per cow, number of cows per sire, and length of the period of data collection. Heritability of milk yield was in agreement with de Roos et al. (2004), but estimates of $\mathrm{h}^{2}$ for fat and protein yields differed and were the highest in the middle and lowest at the beginning of lactation. Heritability estimates for fertility traits (CFI and CLI) were in agreement with those of Mitchell et al. (2005).

Some authors have reported a positive relationship between milk yield and MUN (Godden et al., 2001; Stoop et al., 2007), whereas others found it to be negative (Ismail et al., 1996; Trevaskis and Fulkerson, 1999). The current research used a random regression

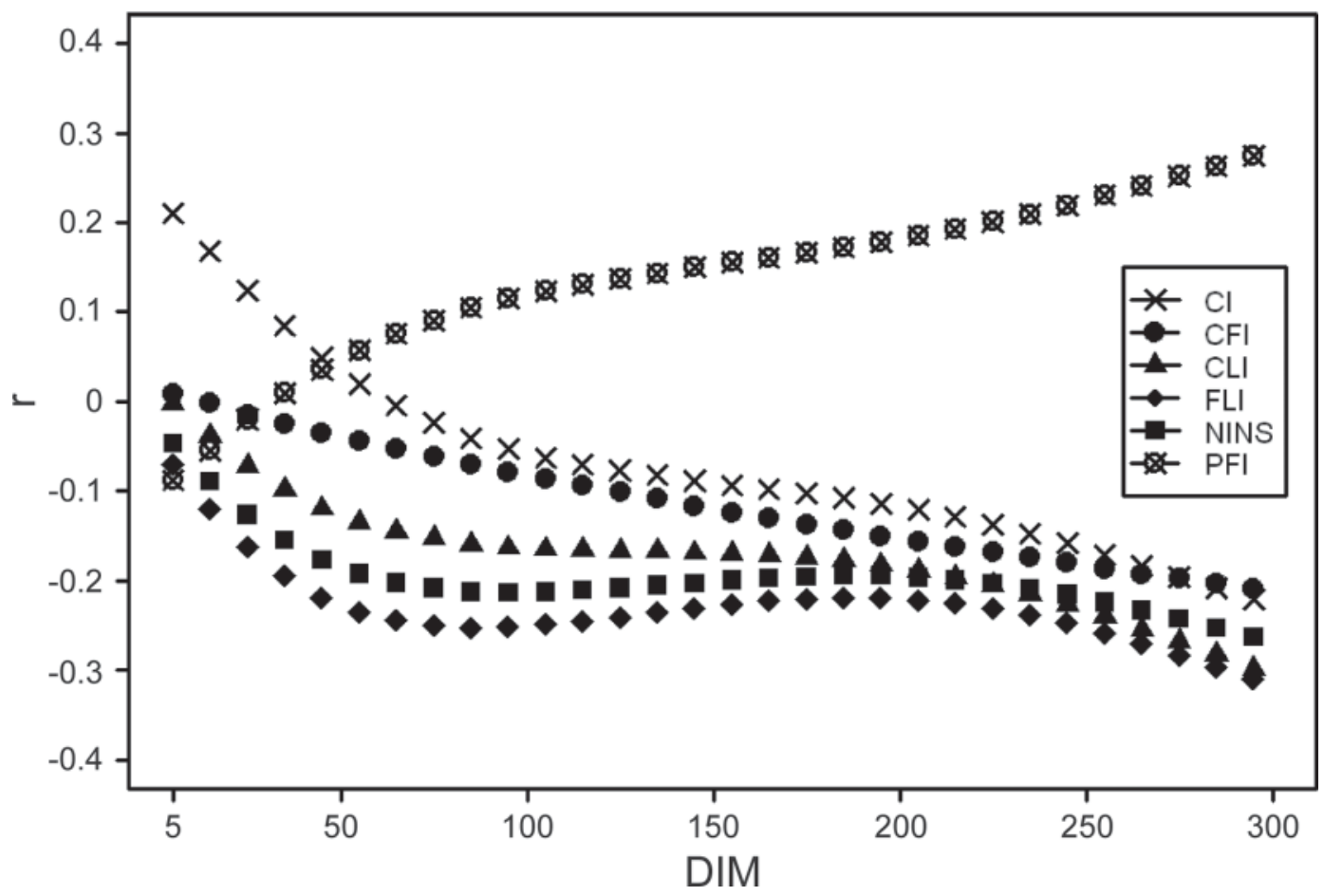

Figure 2. Genetic correlations between MUN and fertility traits of first-lactation Swedish Holstein cows during $300 \mathrm{~d}$ of lactation, based on the random regression model. $\mathrm{CI}=$ calving interval; $\mathrm{CFI}=$ interval from calving to first insemination; CLI $=$ interval from calving to last insemination; FLI = interval from first to last insemination; PFI = pregnancy at first insemination; NINS $=$ number of inseminations to pregnancy. 


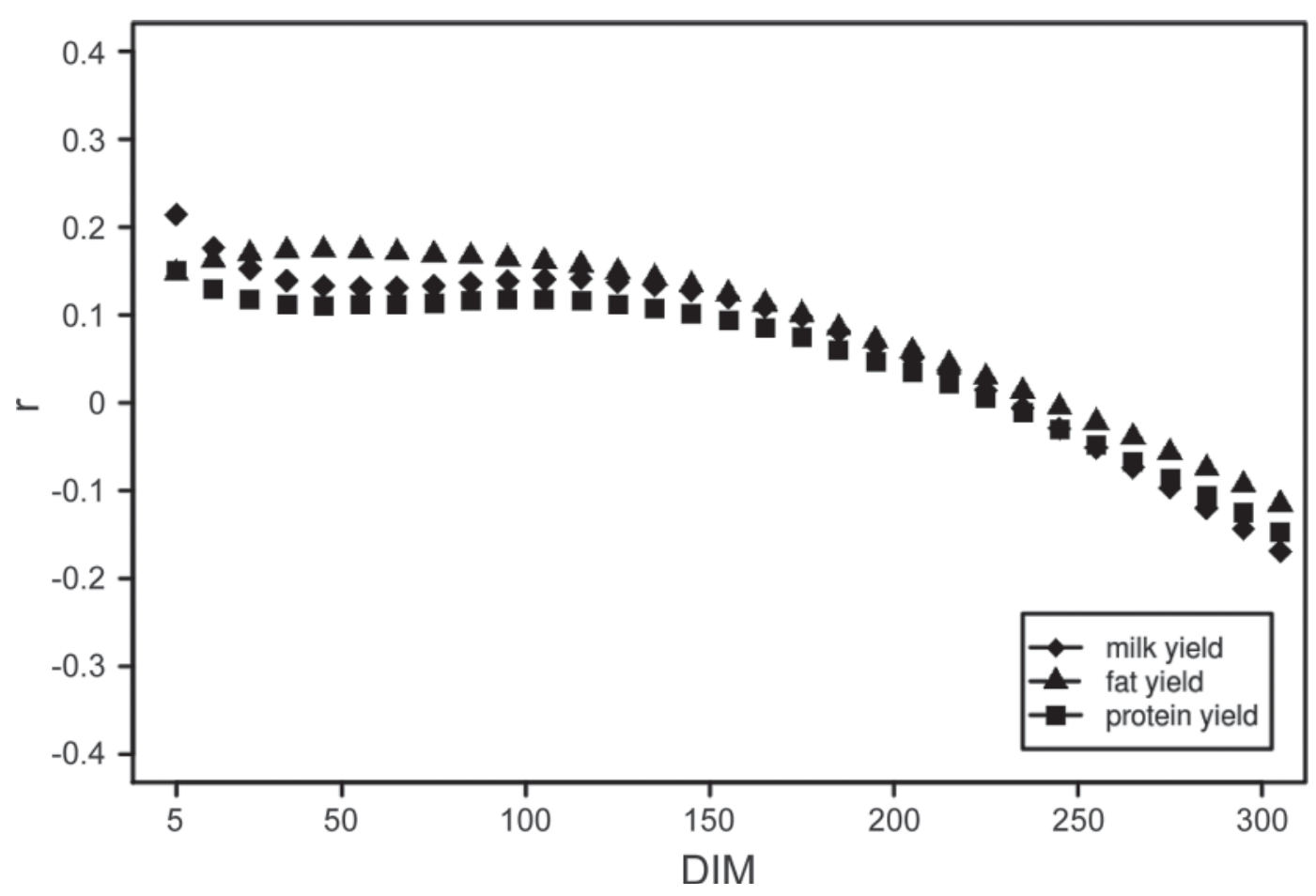

Figure 3. Genetic correlations between MUN and milk production traits of first-lactation Swedish Holstein cows during $300 \mathrm{~d}$ of lactation, based on the random regression model.

model, which allowed changes of correlation during lactation. Therefore, our result (positive correlation at the beginning and negative at the end) is not necessarily contradictory to results from any of the above-mentioned studies. However, other authors, using random regression models, found no correlations between MUN and milk production or fertility (Wood et al., 2003; de Roos and De Jong, 2006; Miglior et al., 2007). However, de Roos and De Jong (2006) did not simultaneously estimate genetic correlations between MUN and other traits, but correlated bull EBV for MUN from their random regression analysis with official national EBV for milk yield and fertility. Wood et al. (2003) used only the first random regression coefficient (the average level) to calculate genetic correlations, and thus, only reported one value.

\section{Fertility}

Mitchell et al. (2005) found a positive genetic correlation of wet chemistry MUN with days open (CLI) of 0.21 and negative correlations with CFI and PFI of -0.14 and -0.06 , respectively. However, all correlations were considered nonsignificant because of the small data set (at most 6,780 cows). The positive correlation of wet chemistry MUN with CLI reported by Mitchell et al. (2005) is contradictory to the negative genetic correlation between infrared MUN and days open (CLI) found in the current research. However, it has been suggested that wet chemistry MUN and infrared MUN are 2 genetically different traits (Mitchell et al., 2005). Moreover, Mitchell et al. (2005) estimated only a single breeding value, corresponding to the average level of MUN.

Genetic correlations of MUN with PFI and CI $(-0.10$ and 0.20 , respectively) at the beginning of lactation suggest that increased MUN leads to decreased fertility, which is in agreement with findings of other authors. However, those correlations changed during lactation to 0.28 (PFI) and $-0.22(\mathrm{CI})$, which suggests a positive relation between MUN and fertility in later stages of lactation. Moreover, correlations of MUN with CFI, CLI, FLI, and NINS, also suggest a positive association between MUN and fertility. They were close to zero at the beginning of lactation but decreased to -0.21 , $-0.31,-0.32$, and -0.27 , respectively, at $\mathrm{d} 300$. That is contradictory to findings of other authors, who have reported that decreased conception rate is associated with increased urea concentrations due to high levels of CP in the diet (Barton et al., 1996; Butler, 1998).

Yoon et al. (2004) reported a positive phenotypic association between urea and days open, stating that cows with MUN concentrations $>18 \mathrm{mg} / \mathrm{dL}$ had more days open (CLI) than cows with MUN concentrations $<18$ 
$\mathrm{mg} / \mathrm{dL}$. However, no influence of MUN on frequency of inseminations was found (Yoon et al., 2004). In addition, Butler et al. (1996) reported that concentrations of MUN >19 mg/dL were associated with decreased pregnancy rate. Nonetheless, such MUN concentrations are much higher than the values from the current project.

The positive phenotypic correlation between MUN and milk yield in the first half of lactation can be explained partly by the higher protein requirements of cows with high milk production. Increased protein supplementation provides more amino acids for milk synthesis, can increase available energy through deamination of amino acids, and may change the efficiency of nutrient utilization (Chalupa, 1984). At the same time, deamination of amino acids increases drainage of nitrogen in terms of urea through urine and milk (Yoon et al., 2004).

The positive genetic association between MUN and fertility found in the current research is contradictory to results of other authors who have reported a negative association between the 2 traits. Generally, high concentrations of urea are associated with decreased fertility, due to the toxicity of urea as well as negative energy balance, which is one of the factors associated with increased MUN concentrations. It should be emphasized that the negative relationships of MUN with fertility, reported by other authors, are phenotypic. In the current study, phenotypic correlations were close to zero. The reported genetic correlations only suggest a positive association between MUN and fertility on a genetic level. This may mean that in a population with a moderate MUN concentration, such as in the current study, selection for improved fertility could increase urea concentration in milk, but only to a small extent. Moreover, when interpreting the current results, the magnitude of the estimated correlations as well as their standard errors must be considered to avoid drawing far-reaching conclusions. It is important to remember that the presence of a genetic correlation may suggest that the traits share part of the underlying genes. However, due to the complexity of the traits and insufficient knowledge of their genetic background, it is difficult to explain fully the mechanism of changes in genetic correlation during lactation. We can hypothesize that different genes are active in different stages of lactation and that their interaction may change with time, resulting in changes in genetic correlation.

\section{CONCLUSIONS}

Estimated heritability of MUN and the 6 fertility traits ranged from 0.16 to 0.18 and from 0.02 to 0.05 , respectively. This confirms that only a small propor- tion of phenotypic variation is attributable to genetics and makes those traits less amenable to analysis and genetic improvement. A weak positive relationship between breeding values for MUN and fertility was found using a random regression model. This finding was confirmed by a multi-trait model. Phenotypic correlation between MUN and fertility was close to zero. The analyzed group of cows had a moderate level of MUN concentration. In such a population, MUN concentration may increase slightly due to selection for improved fertility.

\section{ACKNOWLEDGMENTS}

Anna Wolc and Tomasz Strabel (Department of Genetics and Animal Breeding, Poznan University of Life Sciences, Poland) provided many useful points with respect to the performed analysis, and their contribution is acknowledged.

\section{REFERENCES}

Baker, L. D., J. D. Fergunson, and W. Chalupa. 1995. Responses in urea and true protein feeding schemes for protein of milk to different dairy cows. J. Dairy Sci. 78:2424-2434.

Barton, B. A., H. A. Rosar, G. W. Anderson, B. P. Grindle, and D. J. Carroll. 1996. Effects of dietary crude protein, breed, parity, and health status on the fertility of dairy cows. J. Dairy Sci. 79:2225-2236.

Bastin, C., L. Laloux, A. Gillon, F. Miglior, H. Soyeurt, H. Hammami, C. Bertozzi, and N. Gengler. 2009. Modeling milk urea of Walloon dairy cows in management perspectives. J. Dairy Sci. 92:3529-3540.

Butler, W. R. 1998. Review: Effect of protein nutrition on ovarian and uterine physiology in dairy cattle. J. Dairy Sci. 81:2533-2539.

Butler, W. R., J. J. Calaman, and S. W. Beam. 1996. Plasma and milk urea nitrogen in relation to pregnancy rate in lactating dairy cattle. J. Anim. Sci. 74:858-865.

Chalupa, W. 1984. Discussion of protein symposium. J. Dairy Sci. 67:1134-1146.

Cottrill, B., H. J. Biggadike, C. Collins, and R. A. Laven. 2002. Relationship between milk urea concentration and the fertility of dairy cows. Vet. Rec. 151:413-416.

de Roos, A. P. W., and G. De Jong. 2006. Genetic parameters of testday milk urea in Dutch dairy cattle. Commun. No. 1:202-396 in Proc. 8th World Congress on Genetics Applied to Livestock Production, Belo Horizonte, Brazil.

de Roos, A. P. W., A. G. F. Harbers, and G. De Jong. 2004. Random herd curves in a test-day model for milk, fat, and protein production of dairy cattle in the Netherlands. J. Dairy Sci. 87:2693-2701.

Eicher, R., E. Bouchard, and M. Bigras-Poulin. 1999. Factors affecting milk urea nitrogen and protein concentrations in Quebec dairy cows. Prev. Vet. Med. 39:53-63.

Fischer, T. M., A. R. Gilmour, and J. H. J. van der Werf. 2004. Computing approximate standard errors for genetic parameters derived from random regression models fitted by average information REML. Genet. Sel. Evol. 36:363-369.

Frigo, E., C. D. Dechow, O. Pedron, and B. G. Cassell. 2010. The genetic relationship of body weight and early-lactation health disorders in two experimental herds. J. Dairy Sci. 93:1184-1192.

Godden, S. M., K. D. Lissemore, D. F. Kelton, K. E. Leslie, J. S. Walton, and J. H. Lumsden. 2001. Factors associated with milk urea concentrations in Ontario dairy cows. J. Dairy Sci. 84:107-114.

Guo, K., E. Russek-Cohen, M. A. Varner, and R. A. Kohn. 2004. Effects of milk urea nitrogen and other factors on probability of conception of dairy cows. J. Dairy Sci. 87:1878-1885. 
Gustafsson, A. H., and D. L. Palmquist. 1993. Diurnal variation of rumen ammonia, serum urea and milk urea in dairy cows at high and low yields. J. Dairy Sci. 76:475-484.

Hossein-Zadeh, N. G., and M. Ardalan. 2011. Estimation of genetic parameters for milk urea nitrogen and its relationship with milk constituents in Iranian Holsteins. Livest. Prod. Sci. 135:274-281.

Ismail, A., K. Diab, and J. K. Hillers. 1996. Effect of selection for milk yield and dietary energy on yield traits, bovine somatotropin, and plasma urea nitrogen in dairy cows. J. Dairy Sci. 79:662-688.

Kirkpatrick, M., D. Lofsvold, and M. Bulmer. 1990. Analysis of the inheritance, selection and evolution of growth trajectories. Genetics 124:979-993.

Madsen, P., and J. Jensen. 2008. An user's guide to DMU. A package for analyzing multivariate mixed models. Version 6, release 4.7. University of Aarhus, Tjele, Denmark.

Miglior, F., A. Sewalem, J. Jamrozik, J. Bohmanova, D. M. Lefebvre, and R. K. Moore. 2007. Genetic analysis of milk urea nitrogen and lactose and their relationship with other production traits in Canadian Holstein cattle. J. Dairy Sci. 90:2468-2479.

Mitchell, R. G., G. W. Rogers, C. D. Dechow, J. E. Vallimont, J. B. Cooper, U. Sander-Nielsen, and J. S. Clay. 2005. Milk urea nitrogen concentrations: Heritability and genetic correlations with reproductive performance and disease. J. Dairy Sci. 88:4434-4440.
Nousiainen, J., K. J. Shingfield, and P. Huhtanen. 2004. Evaluation of milk urea nitrogen as a diagnostic of protein feeding. J. Dairy Sci. $87: 386-398$.

Rajala-Schultz, P. J., W. J. A. Saville, G. S. Frazer, and T. E. Wittum. 2001. Association between milk urea nitrogen and fertility in Ohio dairy cows. J. Dairy Sci. 84:482-489.

Stoop, W. M., H. Bovenhuis, and J. A. M. van Arendonk. 2007. Genetic parameters for milk urea nitrogen in relation to milk production traits. J. Dairy Sci. 90:1981-1986.

Trevaskis, L. M., and W. J. Fulkerson. 1999. The relationship between various animal and management factors and milk urea, and its association with reproductive performance of dairy cows grazing pasture. Livest. Prod. Sci. 57:255-265.

Wood, G. M., P. J. Boettcher, J. Jamrozik, G. B. Jansen, and D. F. Kelton. 2003. Estimation of genetic parameters for concentrations of milk urea nitrogen. J. Dairy Sci. 86:2462-2469.

Yoon, J. T., J. H. Lee, C. K. Kim, Y. C. Chung, and C. H. Kim. 2004 Effects of milk production, season, parity, and lactation period on variations of milk urea nitrogen concentrations and milk components of Holstein dairy cows. Asian-australas. J. Anim. Sci. $17: 479-484$. 